\title{
LA SELECCIÓN DE LAS/ LOS CANDIDATOS/AS A DIPUTADOS/AS FEDERALES: EL CASO DE TLAXCALA DURANTE EL PROCESO ELECTORAL 2015
}

\author{
The selection of candidates for federal deputies: \\ the case of Tlaxcala during the 2015 electoral process
}




\section{Resumen}

El propósito del artículo es realizar un análisis del proceso de selección de las candidaturas a diputados/as federales por parte del Partido Acción Nacional (PAN), el Partido Revolucionario Institucional (PRI), el Partido del Trabajo (PT) y el Movimiento de Regeneración Nacional (MORENA) en el estado de Tlaxcala, buscando describir la formalidad de la elección de los candidatos de acuerdo a las reglas partidistas, así como el examen de los posibles conflictos, alianzas, compromisos, negociaciones y acuerdos acaecidos en dicho proceso. El marco de reflexión del tema es el aún vigente planteamiento sobre la transición política mexicana y si esto ha sido posible al interior de los partidos, o si se trata sólo de una recomposición de los grupos políticos y/o clase política atendiendo a prácticas políticas de viejo cuño. Así, los resultados de la indagación a través de entrevistas, consultas hemerográficas y documentos institucionales, ayudarán a discutir de forma cualitativa con base en los datos empíricos de caso, hasta qué punto y/o de qué forma dicha transición política ha sido efectiva o concretada y si ha abonado a la democracia mexicana y particularmente al trabajo interno de los propios partidos políticos. Lo anterior independientemente que desde la formalidad del proceso electivo, los resultados indican el triunfo del PRI como resultado de las elecciones del 2015.

Palabras Clave: candidatos, diputados federales, partidos políticos.

\section{Abstract}

The intention of the article is to realize a comparative analysis of the election process of the choice of the candidacies to federal deputies of the National Regeneration Movement (Movimiento de Regeneración Nacional, MORENA), the National Action Party (Partido Acción Nacional; PAN), the Institutional Revolutionary Party (Partido Revolucionario Institucional; PRI) and the Labor Party (Partido del Trabajo; PT) in the state of Tlaxcala, seeking to describe the formality of the choice of candidates according to the partisan rules, as well as the examination of possible conflicts, alliances, commitments, negotiations and agreements happened in the above mentioned process. The framework for discussion of the topic is the still in force exposition on the political Mexican transition and if this has been possible in terms of the internal democracy of the parties, or if it is a question only of an alteration of the political groups and / or political class attending to political practices of old ways. The results of the investigation, obtained through interviews and the study of journalistic data and institutional documents, will help to discuss in a qualitative form with base in the empirical information of the case; up to what point and / or in which way the above mentioned transition has been effective or settled and if it has contributed to Mexican democracy and particularly in the internal work of political parties, independently that from the formality of the elective process, the results indicate the victory of the PRI as a part of elections 2015.

Keywords: candidates, federal deputies, political parties. 


\section{Introducción}

$\mathrm{E}$

l objetivo de este trabajo es realizar un análisis sobre la calidad de la democracia interna en los procesos de selección en cuatro partidos con registro federal en Tlaxcala: el Partido Acción Nacional (PAN), el Partido Revolucionario Institucional (PRI), el Partido del Trabajo (PT) y el Movimiento de Regeneración Nacional (MORENA). En particular, buscamos revisar los procesos de selección de candidatos que tuvieron lugar previo a la contienda electoral realizada en la entidad en 2015. En dicho proceso electoral se eligieron diputados/as federales de mayoría relativa y diputados/as federales de representación proporcional. En este trabajo retomamos algunas de las propuestas de Freidenberg (2006) para el análisis de la democracia en los partidos, con la finalidad de examinar en qué medida dichos partidos guían sus procedimientos para fortalecer su democracia interna.

Para tal efecto, el trabajo está organizado en los siguientes apartados. En el primero, se plantean algunos aspectos teóricos sobre la alternancia política, la democracia interna y la selección de candidatos con la finalidad de que sirvan de guía para el análisis de los datos empíricos. En el segundo apartado, se brinda un panorama del contexto político estatal. En el tercer apartado se presenta un comparativo de los estatutos de los partidos políticos y los procesos de selección formales. En el cuarto intentamos dar respuesta a las preguntas ¿quiénes fueron las candidatas y candidatos?, mientras que en el quinto apartado, se describe y analiza el proceso de selección que tuvo cada institución política en relación a los intereses de los grupos políticos y/o liderazgos al interior de los partidos. En una penúltima sección se comentan los resultados del proceso electoral 2015. Finalmente las consideraciones finales señalan algunos de los retos que tienen los partidos en relación a la construcción de su democracia interna.

\section{Democracia interna y selección de candidatos}

En el presente apartado abordamos dos temas que son centrales para reflexionar sobre la selección de candidatos. Por un lado, se examina la ubicación de dicho proceso como parte de la construcción de la democracia interna de los partidos políticos, y por otro, miramos a la democracia partidista como parte de "la materia prima" para construir y coadyuvar a eso que llamamos alternancia política mexicana.

\subsection{La alternancia política mexicana}

De acuerdo con Elizondo y Nacif (2006), para los años setenta del siglo pasado, los partidos políticos de oposición en México eran considerados como fuerzas meramente simbólicas en el congreso federal. El panorama comenzó a modificarse en 1988 cuando se configuraron fuerzas políticas en dicho recinto representativo para evitar la aprobación de reformas constitucionales, y se aceleró cuando en 1997 por primera vez el PRI perdió la mayoría en la Cámara de Diputados a nivel federal. Así, “... con el PRI sin mayoría en esa Cámara, los votos de los partidos de oposición se volvieron indispensables para poder aprobar el presupuesto y cambios en la legislación" (Elizondo y Nacif, 2006: 8). 
En cuanto a la alternancia en el gobierno, a fines de los años ochenta comenzó a ser una realidad a nivel nacional. En 1989 se reconoció por primera vez una gubernatura de oposición, a la que se sumó en 1992 la de Chihuahua. En 1999 la oposición controlaba 52 de los 100 municipios más poblados del país, y de hecho en este mismo año las 16 delegaciones de la ciudad de México eran gobernadas por el Partido de la Revolución Democrática (PRD), quien desde 1997 tenía la jefatura del Distrito Federal en su poder. Para el año 2000, 11 de las 32 gubernaturas estaban en manos de partidos de oposición. Después de dos gobiernos panistas en la presidencia entre el 2000 y el 2012, ocurrió en este nivel la alternancia con la llegada en este último año nuevamente del PRI a la presidencia, en la figura de Enrique Peña Nieto.

No es cosa menor también reconocer, como lo hacen Elizondo y Nacif (2006: 9), las modificaciones en los organismos y procesos electorales que comenzaron a darse en la política mexicana. En 1990 se creó el Instituto Federal Electoral (IFE), en el que participaron por primera vez magistrados consejeros, sin pertenencia partidista, para dirimir los problemas originados en los procesos electorales. Para 1994 se cambió a la figura del consejero ciudadano y en 1996 se eliminó la presencia del secretario de Gobernación, para darle mayor autonomía al Instituto respecto al presidente de la República y a los partidos políticos.

Las incipientes transformaciones en el sistema político mexicano y con ello el avance de la democracia, parecían ir entramándose con bases principalmente institucionales y mecanismos operativos en las reglas electorales, lo que a final de cuentas parecía tener un peso específico en la competencia política y la dispersión del poder vía la alternancia de gobierno de los partidos políticos en el plano nacional.

Por su parte, Cordera y Sánchez (1996) consideran que fue a partir de 1994 cuando se generan tensiones en el ambiente político nacional debido a una serie de cambios, siendo ya evidente la crisis que sufrían las reglas e instituciones del régimen. Pero mientras ello ocurría, las nuevas formas democráticas no obtenían presencia certera. De manera que lo distinto no se afianza y lo viejo crea mecanismos para mantenerse e incluso permanecer. En opinión de los autores citados:

En México se trata de una transformación del sistema político; se busca realizar un cambio sin poner en riesgo el poder de la coalición gobernante. Hay, en consecuencia, una voluntad de cambio pero también enormes resistencias a las modificaciones de fondo (Cordera y Sánchez, 1996: 7).

La democracia mexicana puede entonces ubicarse en la tensión que ocurre cuando lo que se busca es: "Ir de un régimen 'formalmente democrático' a uno 'realmente democrático' (Cordera y Sánchez, 1996: 8). De ahí que persista la discusión sobre lo que la democracia es y lo que debería ser.

Para dar salida a esta dualidad Giovanni Sartori (1995) considera que tan importante es la prescripción de la democracia como forma legítima de gobierno como fundamental es la manera en que se lleve a la práctica. No se superponen. Por el contrario, se mantiene una junto a la otra: el deber ser, la prescripción, y lo que es, la descripción. El sistema democrático existe en la medida en que se "presione" para que éste ocurra y se proceda con esa intención; siguiendo ese fin. Por lo que Sartori asegura que el término democracia tiene dos funciones, una descriptiva que indica cómo es ese ideal, y otra normativa o persuasiva, que a la vez que evalúa indica también la dirección que se tendría que seguir. Ambas definiciones no se pueden separar ni tampoco reemplazar. Así lo explica el autor: 
El problema de definir la democracia es doble, porque exige como si dijéramos ambas definiciones, la descriptiva y la prescriptiva. Una no puede existir sin la otra y, simultáneamente, una no puede ser sustituida por la otra. Para evitar un mal comienzo debemos, por tanto, conservar en la mente que: a) el ideal democrático no define la realidad democrática y, viceversa, una democracia real no es ni puede ser una democracia ideal; yb) que la democracia resulta de, y es conformada por, las interacciones entre sus ideales y su realidad, el empuje del deber y la resistencia... (Sartori, 1995: 27).

Con esta definición en mente, como dice Sartori, la democracia se entiende como un proceso, una relación de fuerza. Es en el ejercicio o ejecución donde se hace evidente, según este mismo autor: "el empuje del deber y la resistencia del es."

\subsection{Selección de candidatos}

En opinión de algunos autores los partidos políticos han sido uno de los temas relevantes de la ciencia política moderna (Montero y Gunther 2003 en Alcántara y Cabezas, 2013: 27). Ya desde los primeros trabajos, en el transcurso del siglo XX, según Alcántara y Cabezas, se pudieron conocer reflexiones que apuntaban a las relaciones de poder dentro de los partidos políticos que planteaban el problema de la dominación de los líderes sobre los afiliados. Esto llevó a caracterizar, en lo sucesivo, a los partidos políticos como organizaciones oligárquicas que buscaban dominar, conducir o controlar a su militancia.

Tanto desde el planteamiento de Cordera y Sánchez (1996), sobre la particular transición mexicana, como desde el de Sartori (1995), y conforme a la definición de democracia, existe una veta de continuidad: la tensión entre lo real y lo ideal. Misma que, en correspondencia, llega a los partidos políticos; de ahí que se considere que:

En los procesos de transición, los partidos son principalísimos actores conscientes de la labor que realizan. En esos momentos, su finalidad primordial es el establecimiento de procedimientos democráticos imparciales, pues más que competir por el poder están construyendo las bases del nuevo Estado. En cierta forma, dejan de ser singularidades en búsqueda de un beneficio político directo e inmediato para transformarse en formadores y consolidadores del Estado democrático de derecho (Cárdenas, 2001: 49).

Los partidos políticos son una parte central de la democracia mexicana y analizar la manera en que proceden implica hacer confluir lo ideal con lo real. Bajo esta intención es que han surgido una serie de categorizaciones para identificarlos desde la teoría de partidos. El seguimiento que hace Reveles (2007), a partir de la tipología de Gunther y Diamond, pone de manifiesto la diversidad en el mismo sistema de partidos, pero también al interior de los propios partidos. Por su parte, Michels (1983) considera que los partidos políticos tienen una naturaleza de organización oligárquica y no democrática en su interior. Aunque reconoce que son indispensables e insustituibles en las democracias, también lo son las diferencias de intereses. 
Sartori (1980) definió a los partidos políticos como: “...cualquier grupo político identificado por una etiqueta oficial que se presenta a las elecciones y puede sacar en elecciones (libres o no) candidatos a cargos públicos." En este sentido, es importante prestar atención a las funciones de los partidos políticos, ya que según Vallés (2006) básicamente son dos: a) La trasmisión de las diferentes aspiraciones que emanan de los grupos sociales hacia las instituciones estatales con la capacidad de convertirlas en decisiones vinculantes y b) el intento de legitimar ante aquellos grupos las decisiones adoptadas por las instituciones públicas.

Según Pilar Gangas (s.f.), a pesar de la enorme cantidad de libros y temas producidos a lo largo del pasado siglo y lo que va de este, quizás el tema más relevante ha sido el de la democracia, sus condiciones de durabilidad y efectividad. Dentro del tema de los procesos democráticos el de la democracia interna de los partidos ha jugado un papel central.

Flavia Freidenberg (2006) nos ha brindado una definición de la democracia interna que tiene que ver con la competencia, la adopción de valores democráticos, mecanismos competitivos, participación de los afiliados y el control político:

La democracia interna en un partido supone la adopción de los principios de este sistema político en el interior de la organización. Desde una perspectiva pluralista eso significa la inclusión del criterio de competencia, adopción de valores democráticos tales como la libertad de expresión y la libertad de elección para sus miembros y, por tanto, utilizar mecanismos competitivos en el proceso de toma de decisiones, la participación del afiliado en la formación de la voluntad partidista y la existencia de canales que permitan el ejercicio efectivo del control político. (Freidenberg, 2006: 3).

Para lograr lo anterior, nos dice la misma autora, se deben cumplir una serie de requisitos, entre los más importantes se cuentan los siguientes:

Garantías de igualdad entre los afiliados y protección de los derechos fundamentales en el ejercicio de su libertad de opinión; mecanismos de selección de candidatos a cargos de representación (internos o externos) competitivos; participación de los afiliados en los órganos de gobierno, sin discriminación en la representación de los diversos grupos que integran la organización; activa influencia de los diversos grupos en la discusión y formación de las posiciones programáticas y elaboración de propuestas del partido y en las decisiones comunes que éste tome; respeto del principio de mayoría, que haga que las decisiones sean tomadas en función de la agregación mayoritaria de las voluntades individuales y garantías para las minorías; $y$ control efectivo por parte de los militantes de los dirigentes, a través de procesos que castiguen o premien a los que toman las decisiones (Freidenberg, 2006: 25).

Un aspecto importante que señala Freidenberg (2006) es que no existe un sólo grado de democracia interna. Hay diversos grados como partidos más o menos democráticos existen. El asunto es transitar de un partido oligárquico que cierra el paso a la participación de sus militantes de base a un partido 
abierto y democrático. Para explorar el nivel de democracia interna, esta misma autora propone estudiar la presencia de procesos en el funcionamiento interno y la forma en que tienen lugar tales procesos. Las dimensiones para realizar esta observación son las siguientes:

1. Selección de candidatos a cargos de elección popular y de autoridades partidistas;

2. Participación de minorías y sectores sociales sub representados (mujeres, jóvenes, grupos étnicos) en el proceso de toma de decisiones y en la definición programática del partido;

3. Rendición de cuentas de los candidatos, cargos públicos y autoridades del partido a las bases.

Es importante señalar que, si bien Freidenberg (2006) líneas arriba señala los supuestos que nos permiten explicar la democracia interna dentro de un partido político (competencia, libertad de expresión, libertad de elección, toma de decisiones, participación de los afilados y canales para el ejercicio del control político) y que de alguna manera fungirían como variables independientes en el modelo de esta autora, en este artículo vamos a referirnos específicamente a dos variables. Por una lado, a la normatividad interna para la selección de candidatos, y por otro; al peso de los grupos políticos o los liderazgos carismáticos al interior de cada uno de los partidos. Estos dos aspectos los desarrollaremos más adelante.

\section{El contexto político tlaxcalteca}

Prácticamente los estudios académicos sobre las elecciones de diputados/as federales en Tlaxcala son inexistentes. Cazarín (2010) realizó un estudio cuantitativo de los resultados para la elección de diputados/as en Tlaxcala en el 2009 con la intención de analizar cuáles serían los posibles escenarios políticos que podrían establecerse para la entidad. Su estudio arrojó que en Tlaxcala para el año electoral abordado, los tres distritos federales fueron ganados por el Partido Acción Nacional (PAN), justamente la fuerza política que gobernaba la entidad en dicho año. Con un porcentaje de $36.91 \%$ en el Distrito I de Apizaco, el $38.73 \%$ en el Distrito II de Tlaxcala y un $37.51 \%$ en el Distrito III de Chiautempan. El PAN ganó con poco más de la tercera parte de los votos. Esta tendencia se confirma con el total de los votos para el PAN, ya que fue de 37.70\% (Cazarín, 2010: 177).

El triunfo del PAN contrastó con la tendencia nacional, en donde el PRI ganó para 2009 la mayoría de las curules de diputados/as a nivel federal, ante una presidencia encabezada por un gobierno panista. Y no obstante la tendencia ganadora del PAN en Tlaxcala, para las elecciones federales de diputados/as de ese año, en las elecciones del 2010 para gobernador, el PRI volvió a lograr el triunfo y con ello regresó a gobernar Tlaxcala después de dos periodos en los que el PRD (1998) y el PAN (2004) ganaron las elecciones. Como Cazarín lo señala (2010:162), para el año del 2009 era ya muy clara la alternancia no sólo en la gubernatura, sino en los diversos niveles de gobierno en Tlaxcala, caracterizada por el transfuguismo político, la prevalencia de los tres más importantes partidos políticos (PRI, PRD y PAN) y la pérdida histórica de la hegemonía priísta.

Estos aspectos que definen la alternancia y el gobierno dividido en Tlaxcala, han sido ya analizados como factores claves del fenómeno político en la entidad. En una interpretación de la alternancia a ni- 
vel de la gubernatura, Rodríguez y Veloz (2011, 2013 y 2014) señalan que en 1998 y 2004 para el caso tlaxcalteca, uno de los elementos explicativos centrales han sido las rupturas al interior del PRI para la elección de candidato a gobernador. Los dos candidatos triunfantes, Alfonso Sánchez Anaya y Héctor Ortiz Ortiz, fueron militantes del PRI que decidieron salirse de este partido político ante la imposibilidad de su postulación y debido al autoritarismo en la selección de candidatos. El primero ganó con una coalición encabezada por el PRD, mientras que el segundo logró el triunfo, también bajo una alianza, con el cobijo del PAN. De acuerdo con Rodríguez y Veloz, en ambos casos el voto lo orientó el candidato basado en sus relaciones y estructuras políticas preexistentes y no sustentado en una plataforma electoral. En resumen, las elecciones de 1998 y 2004 fueron ganadas por la oposición al PRI, producto de las debilidades internas de éste partido tras la salida de dos de sus más importantes militantes, quienes en alianza partidaria y con sus preexistentes relaciones políticas lograron mantener una estructura y unidad en torno a sus figuras personales.

Para el 2010 el triunfo de la gubernatura correspondió al PRI, con el candidato Mariano González Zarur. A diferencia de los dos procesos anteriores (1998 y 2004), el PRI mantuvo la unidad con el candidato y realizó una alianza con el Partido Verde Ecologista de México (PVEM), para formar una coalición que finalmente resultó ganadora. En este proceso el PRI aprovechó ahora las diferencias internas del PRD y el PAN, y logró regresar después de dos periodos de gobierno a la gubernatura de Tlaxcala.

Un rasgo importante de mencionar es que la alternancia en Tlaxcala a nivel de la gubernatura tiene como componente una fuerte competencia electoral, ya que no ha existido en los comicios una aplastante mayoría de alguna de las tres principales fuerzas políticas (PRI, PAN, PRD), siendo más bien cerrada. Por ejemplo, en 1998 el PRD ganó con el 45.2\% y PRI como segunda fuerza política obtuvo 43\%; para 2004 el PAN tuvo una votación del $34.9 \%$ y el PRI 34\%; para el 2010 el PRI ganó con un el 46.5\%, mientras que el PAN logró 38.9\% (Rodríguez y Veloz, 2011: 88).

Ahora bien, esta tendencia a nivel del análisis de las elecciones para gobernador, en opinión de Rodríguez y Veloz (2011, 2013 y 2014), es la que prevalece en los diferentes procesos electivos tlaxcaltecas en prácticamente las últimas dos décadas. Es decir, en el congreso estatal como en los municipios se advierte la competencia electoral de los tres principales partidos políticos (Reyes del Campillo, 2014 y Bustamante y Linares, 2014), aunque no únicamente ellos ya que participan otras fuerzas políticas más pequeñas con algunos triunfos.

Como se pondrá de manifiesto más adelante, en una sección del artículo sobre los resultados electorales para la elección de diputados/as federales en el 2015, si bien el PRI ganó los tres distritos electorales de Tlaxcala, no lo hizo con una aplastante mayoría. Obtuvo el triunfo en dos distritos con la tercera parte de los votos y en otro con casi la cuarta parte, comicios en los que otras fuerzas políticas como MORENA, PRD y PAN tuvieron una cantidad de votos importante. Tendencia que como ya se ha caracterizado en esta sección del artículo, al menos desde fines de la década de los noventa del siglo pasado, se ha manifestado progresivamente, y a partir de los cual se puede hablar de una pluralidad política en Tlaxcala. Además las alianzas partidarias y la unidad en torno a una candidatura pueden marcar la posibilidad de ganar, tanto en el nivel de la elección para gobernador como en los comicios para diputados/as y presidentes/as municipales.

En la siguiente sección se hará una comparación en relación a los candidatos del PAN, PRI, PT y MORENA; en lo que concierne al proceso interno de cada partido previo a la definición de sus candidatos. 


\section{Los estatutos de los partidos políticos: PAN, PRI, PT y MORENA}

Conforme al planteamiento de Freidenberg (2006) la selección de candidatos es una de las dimensiones que permiten observar el nivel de democracia interna de los partidos. Bajo esta consideración, en este apartado se revisará lo establecido en los estatutos de las instituciones políticas en cuestión, que corresponde a su normatividad interna, específicamente en lo que a la designación de candidatos a cargos de representación popular se refiere. En contraparte, en el apartado cinco, se expondrá lo ocurrido durante el proceso de elección, respecto a la actuación de los grupos políticos y/o los liderazgos al interior del partido.

Por lo que se refiere al Partido Acción Nacional (PAN), en el Título octavo "De la selección de candidatos a cargos de elección popular" de sus estatutos queda establecida la forma de selección de sus candidatos/as. El capítulo segundo está referido al método de selección de candidatos. En este se establece que los métodos de selección son: votación por militantes, designación, y elección abierta de ciudadanos. Para tal efecto, el Comité Ejecutivo Nacional dispone de las convocatorias y modalidades para la elección. El artículo 84 define que será en el "Reglamento" donde quedará establecido el procedimiento para la elección de sus candidatos.

Por lo que toca al PRI en el capítulo III de sus estatutos aparece "De la postulación de candidatos a cargos de elección popular". En la Sección 1 "De los requisitos para ser candidatos", se establece que la militancia, de uno a más años según sea el cargo, es condición primigenia para una postulación, lo mismo que demostrar lealtad al partido, haber sido cuadro o dirigente y no haber sido "dirigente, candidato ni militante de partido o asociación política antagónica”. La lealtad al partido parece factor decisivo de la carrera política de cualquier militante. Además de mostrar una conducta pública adecuada, cumplir las disposiciones del "Código de Ética Partidaria”, así como acreditar conocimientos de los Documentos Básicos del Partido con base en los "cursos de capacitación y formación política que impartirá el Instituto de Capacitación y Desarrollo Político A. C.", en los estados y en el DF. De acuerdo al artículo 181, los procedimientos para la postulación de candidatos son los siguientes: I) Elección directa, II) Convención de delegados, ${ }^{5}$ III) Por Comisión para la Postulación de Candidatos. ${ }^{6}$ En todos ellos, se asegura, privan los principios de "voto libre, directo, secreto e intransferible".

En el caso del PT en el capítulo XXX de sus estatutos, "De las elecciones", se considera que la elección de los candidatos de elección popular se puede realizar por: 1) la Convención Electoral Nacional o 2) por la Convención Electoral Estatal o del Distrito Federal. Pero no se definen puntualmente los procedimientos a seguir. La fracción III del artículo 118 considera que la Comisión Ejecutiva Nacional, Estatal o

4- En el apartado III del artículo 187 se considera que para ser candidato es necesario, además, contar con apoyo en la estructura del partido, en los comités seccionales, municipales, en los diferentes organismos de mujeres, juveniles, -las que define en el artículo 31 como organizaciones nacionales- de los consejeros políticos y/o por miembros afiliados. Y en el artículo 188 se especifica la proporción que debe guardar ese apoyo que va, en algunos casos, del 10\% al 25\%.

5- En el artículo 184 se describe la formación de una convención de delegados para llevar a cabo la elección. Es una modalidad más o menos incluyente, si se considera que la elección directa implica mayor participación de militantes.

6- Se describe en el artículo 184 Bis. Se conforma por siete miembros que son designados por el Consejo Político Nacional o Estatal, depende de la elección que se trate. 
del Distrito Federal; según sea el caso, podrá constituirse en Convención Electoral reconociéndose como máximo órgano electoral equivalente al Congreso Nacional, Estatal o del Distrito Federal, Distrital, Municipal o Delegacional, para que se constituya en Convención Electoral Nacional, Estatal o del Distrito Federal; Distrital, Municipal o Delegacional. Por otra parte, los estatutos del PT condicionan la elección del candidato a cualquier cargo de elección popular a ser militante o afiliado al partido, siempre bajo la idea de una organización democrática interna. Además, y por congruencia ideal, se expresa la necesidad de que el candidato comulgue con la ideología del partido, que, conforme a los estatutos, se trata de la izquierda socialdemócrata por la cercanía que manifiestan tener con la población más desfavorecida de la sociedad. Asimismo, el artículo 119 señala que la elección de los candidatos se podrá realizar por sus respectivas instancias a través de los mecanismos de votación previstos en los Estatutos. Los candidatos habrán de reunir las siguientes características: a) Lealtad al proyecto y a los postulados del Partido del Trabajo, b) congruencia con los principios del Partido del Trabajo y su práctica política, c) no tener antecedentes de corrupción y d) compromiso con las luchas sociales y desarrollo del Partido del Trabajo.

En lo que respecta al partido Movimiento de Regeneración Nacional (MORENA), en el apartado V de sus estatutos, se definen las directrices de los procesos electorales internos. Se señala que los candidatos, según lo marcan las orientaciones generales contenidas en la introducción, deben conducirse con apego a los derechos y la democracia para responder así a los objetivos superiores del pueblo de México, y no buscar cargos para obtener privilegios.

Según los estatutos de MORENA el proceso de elección de candidatos/as federales plurinominales inicia un año antes bajo el siguiente esquema: 1) Publicación de convocatoria, el Comité Nacional de Elecciones propone al Comité Ejecutivo Nacional (CEN) las convocatorias que serán publicadas en un medio impreso de circulación nacional 2) Notificaciones domiciliarias a los militantes sobre la realización de la asamblea donde habrá de efectuarse la elección, 3) Inscripción en el CEN, 4) Asambleas Distritales, donde se elegirán a 10 candidatos/as (cinco hombres y cinco mujeres) y 5) Insaculación por circunscripción. ${ }^{7}$

Cuadro 1. Formas de elección a cargos de elección popular por partido

\begin{tabular}{|c|c|c|c|c|}
\hline Partido político & $\begin{array}{c}\text { Votación } \\
\text { militancia }\end{array}$ & Designación & $\begin{array}{c}\text { Elección } \\
\text { abierta } \\
\text { ciudadanos }\end{array}$ & $\begin{array}{c}\text { Votación } \\
\text { delegados }\end{array}$ \\
\hline PAN & $\mathrm{X}$ & $\mathrm{X}$ & $\mathrm{X}$ & $\mathrm{X}$ \\
\hline PRI & $\mathrm{X}$ & $\mathrm{X}$ & & $\mathrm{X}$ \\
\hline PT & $\mathrm{X}$ & & & \\
\hline MORENA & & & & \\
\hline
\end{tabular}

Fuente: Elaboración propia en base a los estatutos de los partidos políticos. 
En resumen, como se desprende de lo planteado en este apartado las formas de elección de los candidatos/as a cargos de elección popular son diversas (véase cuadro 1). Por un lado, el PAN y el PRI cuentan con tres formas de elección, llama la atención que el primer partido abre la posibilidad de una elección abierta a la ciudadanía; por otro lado el PT y MORENA sólo cuenta con una posibilidad; el PT a través de la votación de sus delegados y MORENA a través de la votación de su militancia.

\section{4. ¿Quiénes fueron los/as candidatos/as?}

Los procesos de selección de los/las candidatos/as a cargos de elección popular en los partidos políticos dice mucho de las prácticas de las dirigencias y de las militancias para la obtención del poder. En este apartado presentamos información sobre quiénes fueron los/las candidatos y quiénes los/las eligieron, en los casos del PAN, PRI, PT y MORENA (véase Anexo). Todos ellos con particularidades específicas pero también con coincidencias en las formas de elección.

En el PAN se presentan como candidatos/as dos hombres y una mujer con experiencia en cargos de elección popular en el ámbito local. Dos de ellos presidentes municipales en funciones quiénes piden licencia para contender por la diputación y uno más ex presidente municipal.

El PRI elige a dos mujeres y a un hombre. Los tres con trayectoria política en los escenarios estatal y nacional. Las dos mujeres ostentan en su trayectoria el haber ocupado el cargo de Consejera Nacional de su partido. En la trayectoria del candidato destaca el haber sido Presidente del PRI nivel estatal y Consejero Nacional de su partido.

Por otra parte, el PT, elige a un hombre y dos mujeres: un expresidente municipal y líder de ese partido en Apizaco, una profesora de la Universidad Autónoma de Tlaxcala y una candidata del equipo de gobierno del Presidente Municipal de Santa Ana Chiautempan de extracción perredista.

Finalmente, en MORENA durante el proceso 2015 se eligieron tres candidatos/as para los tres Distritos Electorales de la entidad. Dos hombres y una mujer. Los dos candidatos con amplia experiencia en la administración pública, uno de ellos ex gobernador de Tlaxcala por el PRD y el otro su coordinador de asesores. La candidata del Distrito III destaca por un trabajo legislativo durante su gestión como diputada local (en ese momento por el PRD) impulsando una Ley contra el maíz transgénico y por la defensa del maíz nativo y posteriormente como coordinadora a nivel nacional de los asuntos Indígenas de MORENA.

En resumen, PAN, PRI y MORENA presentan a los/las candidatos/as con más trayectoria en la administración pública y en los partidos políticos. Esto no es de extrañarse debido a que el PAN y el PRI son partidos de una amplia trayectoria en la entidad y cuentan con una sólida estructura partidaria. MORENA, un partido de reciente creación que acogió a diversos grupos militantes del PRD debido a su afiliación de izquierda, atrajo no sólo a los militantes perredistas sino por igual a ciudadanos sin militancia previa. En los datos presentados también destaca que el 50\% de los candidatos/as son mujeres y que la formación profesional más frecuente es la de abogado/a. Con ello tenemos una descripción de los perfiles de los/las candidatos/as en términos de trayectoria, profesión y género. 


\section{Los procesos de selección de candidatos/as}

Cada uno de estos procesos tuvo características específicas, que como se describirá a continuación, en algunos casos distaron de lo planteado en los estatutos. La convocatoria del PAN se dio a conocer el 23 de diciembre de 2014 y en ella se informó que la selección de candidaturas sería vía la votación por militantes en los centros de votación. Hasta el primero de febrero se recibieron propuestas, y el 22 de febrero se eligió a los candidatos por parte de los militantes que aparecieron en la lista nominal del PAN. Para el Distrito I se eligió a Orlando Santa Cruz Carreño; en el II a Miguel Ángel Polvo Rea, y Lilia Caritina Olvera Coronel en el III. Si bien es cierto que formalmente se celebraron asambleas donde los participaron los militantes de este partido, previo a ello se fueron estructurando las candidaturas como propuestas de los grupos políticos dominantes dentro de ese partido en el Estado.

En la entidad se identifican tres grupos políticos fuertes: uno encabezado por la senadora panista Adriana Dávila Fernández; otro encabezado por el ex secretario de gobierno y actual Presidente Municipal de Tlaxcala por el PAN, Adolfo Escobar Jardines; y un último grupo, encabezado por el ex gobernador Héctor Israel Ortiz Ortiz del PAC . Desde esta perspectiva, cada grupo promueve el registro de sus candidatos/as. Veamos quiénes impulsaron las candidaturas. En el distrito I, los cuatro grupos registraron sus candidatos/as; por parte del grupo de Escobar: Juan Bárcenas González, es impulsado para participar en la contienda; del grupo de Ortíz: el munícipe de Huamantla Alejandro Aguilar López se registra como precandidato, del grupo de Dávila: el polémico exalcalde de Apizaco, Orlando Santacruz Carreño. Por lo que toca al distrito II, Miguel Ángel Polvo Rea, es el único candidato que se registra por esta demarcación, es aquí donde las dos principales fuerzas panistas (Escobar y Dávila), hacen coincidir sus intereses, ambos dan muestras de respaldo por la candidatura del munícipe de la Magdalena Tlatelulco' . El distrito III fue reservado para una mujer, bajo esta condición, nuestro supuesto es que Ortiz y Escobar impulsan el registro de Lilia Caritina Olvera Coronel, mientras que el grupo de Dávila de último momento impulsa a Sonia Lilian Rodríguez como su candidata a la diputación.

Como se desprende de los datos anteriores son los grupos políticos los que definen las candidaturas al interior de estos institutos. Los líderes de estos grupos políticos (al igual que en el resto de los partidos políticos) derivan su alto nivel de influencia de: una amplia trayectoria dentro de su partido político, de los recursos económicos que detentan y de las redes de relaciones políticas que han tejido a nivel federal, estatal y municipal. "Los electores no hacen más que ratificar esta elección", como lo planteara Duverger (2002: 378) porque previo a la selección de los candidatos por los electores existió un pre-escrutinio por parte del partido.

Por lo que respecta al PRI en el proceso electoral 2015 para diputaciones federales la forma de elección fue "Convención de delegados," en Tlaxcala comenzó la primera semana de enero con el registro de aspirantes de los distritos I y III. En el Distrito II la designación fue mediante la Comisión de Postulación

8- Las siglas corresponden al Partido Alianza Ciudadana (PAC) de registro local, dirigido por los hermanos Héctor Israel Ortiz Ortiz, quien fue Gobernador del estado por el Partido Acción Nacional (PAN) y ex rector de la Universidad de Tlaxcala, y Serafín Ortiz Ortiz, también ex rector de la misma universidad.

9- Con relación al otro contrincante que había señalado su interés por participar en este proceso, puede referirse a la nota de El Sol de Tlaxcala del 8 de enero de 2015 
de Candidatos. El registro para este último proceso inició el 22 de enero, pero ya desde entonces el panorama parecía concluyente: Rosalinda Muñoz se presentaba como candidata por el Distrito I; Anabel Alvarado por el Distrito II y Ricardo García por el Distrito III.

En lo que respecta al proceso formal, éste dio inicio, en efecto, a través de una convocatoria en diciembre del 2014. Pero esta sólo fue para los distritos I y III, pues el Distrito II con cabecera en la ciudad de Tlaxcala, se sabe que se reserva como una decisión del Comité Ejecutivo Nacional de ese partido -en tanto se trata de la elección mediante la forma Comisión para la Postulación de Candidatos-. Los requisitos y formatos para inscripción de los candidatos se emitieron a principios del mes de enero del $2015^{10}$. A diferencia del resto de los partidos aquí analizados en el PRI el grupo político fuerte es el del gobernador Mariano González Zarur. El impulsó las candidaturas en los distritos I, II y III. Pese a la existencia de otros grupos el hegemónico en términos de influencia práctica e ideológica es el del ejecutivo. Muestra de lo anterior fue que en la primera semana de febrero del 2015, se registran de forma única a Rosalinda Muñoz, Anabel Alvarado y Ricardo García, como los tres candidatos del PRI para los distritos federales por mayoría relativa que tiene Tlaxcala. Dos semanas más tarde, en convención de delegados para la elección de los candidatos a los distritos I y III, se ratificó la designación de los candidatos del PRI. En el caso del Distrito II ${ }^{11}$ se designó el 21 de febrero a Anabel Alvarado como candidata electa ${ }^{12}$.

La decisión sobre los candidatos tomó en cuenta su trayectoria, en sintonía con lo establecido en el capítulo 3 sección 1, y en el apartado III del artículo 187 de sus estatutos; aunque, el impulso que se dio a estas candidaturas desde el ejecutivo estatal fue un elemento determinante. Visto de entrada pareciera que sucede lo señalado por Cordera y Sánchez (1996) sobre las características del cambio hacia la democracia que ocurre en México: ya no se trata más que de una simulación porque la voluntad de cambio está en función de no comprometer los poderes, liderazgos y privilegios. Sin embargo, el efecto que tiene el control de los procesos por parte de los líderes sobre los afiliados caracteriza un tipo oligárquico de partido que denota el dominio y control en su interior como queda sentado por la influencia definitiva y clara del ejecutivo estatal en la vida interna de ese partido

Algunos aspectos a resaltar sobre la trayectoria de los candidatos que les valieron para su postulación son, en el caso de Ricardo García Portilla exfuncionario del gobierno estatal y responsable de las finanzas públicas; además de haber realizado labores de apoyo a su partido en el Senado. Rosalinda Muñoz es hija de Ernesto Muñoz, priista de muchos años, y expresidente del municipio de Tlaxco. Además, Rosalinda Muñoz es cercana a Beatriz Paredes (1987-1992), exgobernadora priista en dicho partido; a ello se suma el respaldo del hijo del gobernador tlaxcalteca Mariano González Aguirre, quien declinó a sus aspiraciones para dar apoyo a la campaña de Muñoz. Por lo que respecta a Anabel Alvarado, participó con Enri-

10- La prensa tlaxcalteca dio cuenta desde enero del 2015 de las aspiraciones a ser elegidos candidatos a diputados/as federales por el PRI, no sólo de los 3 que resultaron electos para la contienda electoral, sino también de algunos otros personajes priistas, como el expresidente municipal de Tlaxcala, Pedro Pérez Lira, y del hijo del gobernador, Mariano González Aguirre. Pérez Lira aspiraba a ser elegido como candidato al distrito 2, y González Aguirre por el distrito 1. Ambos decidieron finalmente no contender y en el caso del segundo apoyar la candidatura de Rosalinda Muñoz.

11- La decisión fue del Consejo Nacional del PRI bajo la forma de Comisión para la Postulación de Candidatos.

12- Tres aspectos resaltan en el proceso de elección al margen de los estatutos: 1) La declinación de prácticamente la mitad de los aspirantes a ser elegidos candidatos a diputados/as federales, 2) la nulidad de señalamientos sobre disputas y conflictos por la designación de las candidaturas, en respuesta al llamado que hizo a la unidad y disciplina partidista, el gobernador del estado de Tlaxcala, de extracción priista, a fines de enero del 2015, una semana antes de que se definieran las candidaturas de manera formal, y 3 ) el apoyo sin discusión que dieron los delegados priistas, provenientes de las estructuras partidarias, a las propuestas de las dos candidatas y el candidato a la diputaciones federales. 
que Peña Nieto exgobernador del Estado de México y actual presidente. Además fungió como secretaria particular de Mariano González Zarur (2011-2017), gobernador del estado de Tlaxcala. Como se deriva de los anteriores datos los tres candidatos con cercanía a personales nacionales y con el ejecutivo de la entidad pueden explicar en buena medida su designación.

El PT inicia su proceso de selección de candidatos/as el lunes 5 de enero de 2015, cuando se informó sobre la apertura para el registro de candidatos que sería hasta el 8 de enero, ya que el 9 darían a conocer los resultados y se aseguraba, desde la voz de su dirigente estatal Silvano Garay Ulloa, que: "el partido hará un análisis minucioso sobre los aspirantes, con la finalidad de escoger a los mejores perfiles y a quienes se encuentren realmente identificados con las causas ciudadanas". ${ }^{13}$ Su interés también consideraba la situación del partido a nivel nacional desde donde se vislumbrara la posible pérdida del registro por lo cual el partido "tiene la obligación de entregar buenos resultados" comentaba Reyes Ruíz, quien sería candidato del Distrito I.

Pero además el dirigente estatal añadía: "el objetivo es ir con candidatos únicos y evitar el proceso de precampañas, toda vez que esto representa gastos infructuosos que se pueden evitar con la selección de candidatos con el perfil adecuado." En este partido no existieron precampañas, no hubo precandidatos, y no se dieron a conocer los nombres de quienes se registraron para ese proceso, tampoco se informó a los militantes sobre los requisitos para la elección. ${ }^{14}$ De ahí que la designación de candidatos, fue supeditada a la necesidad de ese partido de mantener su registro a nivel nacional y local y no se abrió el proceso a la participación de sus militantes. Incluso, desde sus estatutos la elección de candidatos a cargos de representación popular queda a cargo de la votación de delegados por lo que la normatividad interna garantiza la retracción del partido y la flexibilidad conforme su interés, al margen de los procesos democráticos internos.

Formalmente los candidatos se eligieron mediante la Convención Electoral Estatal y se dieron a conocer el 24 de marzo de 2015 en momentos diferentes. El primero ocurrió por la mañana al presentar a la candidata del Distrito II Alejandra Ramírez Ortiz, quien es sobrina de los hermanos Ortiz, actores políticos de amplia trayectoria política y universitaria en el estado. El acto ocurrió en las instalaciones del Partido Alianza Ciudadana en un evento en el que se dieron cita miembros y personajes destacados de este partido y el presidente del PT. Ese mismo día por la tarde, y en un restaurante de la capital tlaxcalteca, el presidente del PT Silvano Garay Ulloa presentó a los otros dos candidatos Reyes Ruíz y Angélica Carreto.

En el caso de MORENA, la forma de elección fue la única permitida por sus estatutos: la votación de la militancia a través de Asambleas Distritales. Los candidatos elegidosfueron los siguientes: Alfonso Sánchez Anaya poreldistrito Ide Apizaco; Marco Antonio CastilloHernándezporeldistritoII de Apizaco;y Ana Lilia Riveraporeldistrito IIIdeZacatelco.Elprocesoparalascandidaturasimplicóvariasetapas:1)De inscripción en el Comité Ejecutivo Estatal y búsqueda de consensos. El proceso inició un año antes cuando los candidatos empezaron a platicar con los miembros estructura del partido para conocer posibilidades de apoyo. ${ }^{15}$

13- Tlalmis, Leonel (2015) Abre PT convocatoria para registro de precandidatos, El Sol de Tlaxcala, 5 de enero de 2015. Disponible en: http://www.oem.com.mx/elsoldetlaxcala/notas/n3661130.htm

14- En esa misma fecha (5 de enero de 2015) el Partido Alianza Ciudadana (PAC) a través de sus dirigentes manifestaba estar en pláticas para formar una alianza de facto. Estos acuerdos serían determinantes para la postulación de Alejandra Ortiz.

15- Entrevista realizada a Marco Antonio Castillo, candidato a diputado federal por el Distrito II, 23 de junio del 2015. 
El criterio de elección fue: el perfil del candidato, el interés de cada uno/a, el curriculum vitae de los aspirantes, la experiencia política y la presencia en el distrito. Algunos desistieron de participar porque esperaban que el partido les diera alguna remuneración importante para realizar la campaña; otros declinando a favor de los que tenían un curriculum vitae más sólido y después de considerar la magnitud del compromiso, lo que significaba entrar a una campaña de esas dimensiones. Al final se van decantando los candidatos, y en la última etapa sólo queda el candidato/a que irá a la elección. ${ }^{16}$ 2) En la segunda etapa se presentan los/las candidatos/as a los Comités Municipales. Una vez que se decide quién es el/la candidato/a, hay que acordar los apoyos que brindarán las estructuras municipales a lo largo de la campaña. 3) La tercera etapa es la de inscripción en la Comisión Nacional de Elecciones.

Algunos aspectos que les valieron a los/las candidatos/as para ser elegidos son los siguientes: Alfonso Sánchez Anaya (1999-2005), médico veterinario, ex gobernador del Estado de Tlaxcala, fundador de la Conferencia Nacional de Gobernadores (CONAGO), ex diputado federal, integrante del Consejo Consultivo de MORENA, entre muchos otros cargos políticos y puestos en el gobierno federal; Marco Antonio Castillo Hernández: médico veterinario, Coordinador de campaña a la gubernatura del ex gobernador Alfonso Sánchez Anaya, Coordinador de Asesores del ex gobernador Alfonso Sánchez Anaya, ex director del CECYTE, profesor universitario, entre otros cargos y puestos; y Ana Lilia Rivera, abogada, Consejera Nacional de MORENA, ex diputada local del PRD, Impulsora en el Congreso Local de la ley de Fomento y Protección al Maíz.

Como en los otros partidos el Comité Ejecutivo Nacional, a través de su líder nacional Andrés Manuel López Obrador tuvo una participación importante. MORENA buscaba no sólo lograr candidatos con una trayectoria reconocida en la administración pública y política apegada a sus estatutos sino que tuvieran la suficiente presencia para lograr el registro de este joven partido político, lo cual, se logró sin ningún contratiempo porque pasó a ser durante las elecciones la tercera fuerza electoral del Estado.

Cuando se miran de cerca los procesos de algunos partidos se da cuenta, utilizando palabras de Ackerman (2015), del carácter estéril de la democracia. La primacía del líder por sobre las militancia es uno de los rasgos que comparten los procesos aquí analizados; el Comité Ejecutivo Nacional aparece en todos los casos como determinante de las decisiones, lo mismo que la designación de candidatos conforme a los intereses, alianzas y compromisos partidistas. Por otra parte, a pesar de la alternancia experimentada en la gubernatura de Tlaxcala (PRI, PAN y PRD) no se modificó el poder de los grupos políticos intra partidarios (sus mecanismos y sus prácticas) en la definición de las candidaturas.

Aquí es importante señalar que este tipo de elección llamada "intermedia" es relevante porque es el antecedente de las elecciones para gobernador. Durante las elecciones intermedias se preparan las estructuras territoriales y logísticas de los partidos políticos, se abren los mecanismos para ir tejiendo redes de apoyo con la sociedad en ciudades y comunidades y se va estructurando la presencia del partido.

16- En el caso de la candidatura de Marco Antonio Castillo, entre los candidatos que se apuntaron a la contienda estaban: Roberto Ramos, ex presidente municipal de San Pablo del Monte por el PRD, dirigente de MORENA en ese municipio y contador público de profesión; Nieves Roldán, secretaria de finanzas de MORENA a nivel estatal, profesora de profesión, proveniente del Movimiento Bases Magisteriales; Arnulfo Corona, profesor de profesión y proveniente del PRD y Francisco Gonzáles, colaborador del ex gobernador Alfonso Sánchez Anaya; entre otros. 


\section{Los resultados del proceso electoral 2015}

Si bien analizar las causas de los resultados obtenidos en las elecciones del 2015 para diputados federales en Tlaxcala no es la intención de este artículo, con la finalidad de no dejar fuera los datos formales producto de la contienda electoral, se hará una breve descripción cuantitativa de los resultados. La idea es mostrar argumentos que confirman la tendencia del pluralismo político en Tlaxcala, relacionándolos con el proceso de selección de candidatos/as para los comicios del 2015.

Actualmente el estado de Tlaxcala está dividido en tres distritos electorales a nivel federal, donde el PRI resultó ganador en todos ellos en los comicios del año pasado. El Distrito 1 tiene cabecera en Apizaco, el Distrito 2 tiene cabecera en Tlaxcala y el Distrito 3 tiene cabecera en Zacatelco, ciudades localizadas geográficamente en el centro-norte, centro-sur y sur del estado, respectivamente (véase Mapa 1).

Mapa 1. Distritos electorales de Tlaxcala, 2015

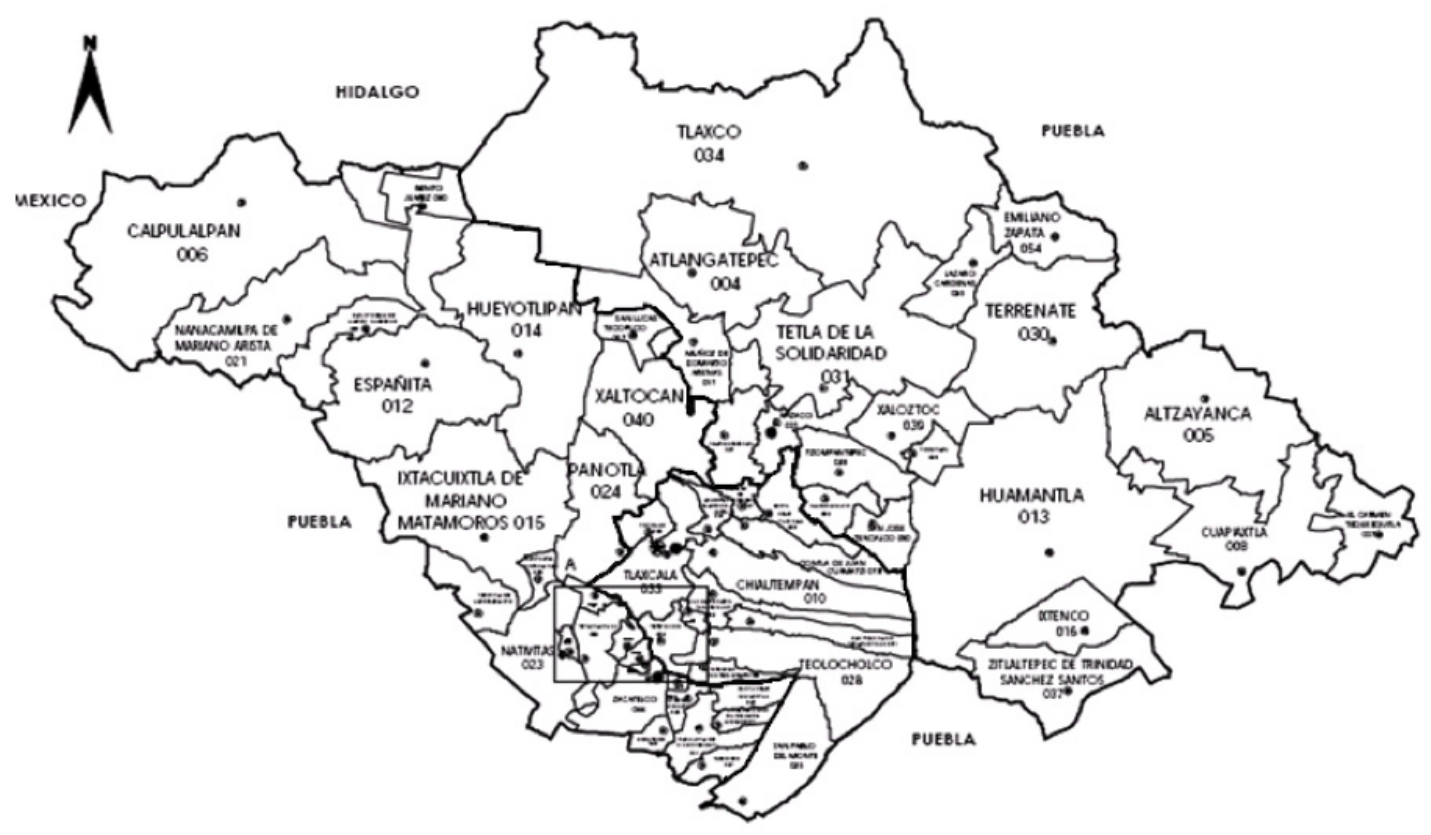

Fuente: Instituto Nacional Electoral (INE)

Como puede observarse en el cuadro 2, en el primer distrito el PRI obtuvo 40012 votos, en el segundo 25922 y en el tercero 25 882. En total los tres candidatos del PRI lograron un total de 94816 votos. Si se comparan los resultados a nivel distrital, en el primero los votos favorecieron con un amplio margen al PRI, en relación al resto de los partidos políticos, siendo MORENA su más cercano competidor con 21 661. En los otros dos distritos, la diferencia fue mucho menor. El PAN en el Distrito 2 logró 21177 votos, y en el tercero Nueva Alianza 16 522; en este último caso la diferencia de votos fue de casi 10000. 
Cuadro 2. Tlaxcala. Elección de Diputados Federales 2015

\begin{tabular}{|c|c|c|c|c|}
\hline \multicolumn{5}{|c|}{ Resultados de elección por mayoría relativa } \\
\hline Partido político & Distrito 1 & Distrito 2 & Distrito 3 & $\begin{array}{c}\text { Total por } \\
\text { partido }\end{array}$ \\
\hline PAN & 17,691 & 21,177 & 12,133 & 51,001 \\
\hline PRI & 40,012 & 25,922 & 28,882 & 94,816 \\
\hline PRD & 4,509 & 12,930 & 13,730 & 31,169 \\
\hline PVEM & 4,992 & 5,823 & 3,534 & 14,349 \\
\hline PT & 4,240 & 20,228 & 8,060 & 32,528 \\
\hline Movimiento Ciudadano & 1,508 & 1,705 & 7,656 & 10,869 \\
\hline Nueva Alianza & 3,028 & 3,958 & 16,522 & 23,508 \\
\hline Morena & 21,661 & 12,219 & 10,101 & 43,981 \\
\hline Partido Humanista & 1,575 & 1,863 & 1,056 & 4,494 \\
\hline Encuentro Social & 3,624 & 3,935 & 1,261 & 8,820 \\
\hline Candidato Indepediente & & & 2,488 & 2,488 \\
\hline Candidatos no registrados & 50 & 79 & 72 & 201 \\
\hline Votos nulos & 6,869 & 6,435 & 5,171 & 18,475 \\
\hline Total por distrito & 109,759 & 116,274 & 110,666 & 336,699 \\
\hline
\end{tabular}

Fuente: Instituto Electoral del Estado de Tlaxcala

Observando cantidades totales de votos en el mismo cuadro 1, el más cercano de los contrincantes del PRI, quien obtuvo 94816 votos, fue el PAN con un total de 51001 votos en total, seguidos de MORENA, PT y PRD, con 43 981, 32528 y 31169 votos respectivamente. Como puede observarse, la diferencia de votos totales entre el PRI y su más cercano competidor fue casi del doble de votos. No obstante, como lo pone en evidencia la cantidad de votos para otros partidos distintos al PRI, es evidente que los partidos políticos en Tlaxcala también tienen una estructura y voto ciudadano que amplía el espectro político en la entidad. Tomando en cuenta que MORENA por primera vez se presentaba en elecciones es un triunfo haber sido la tercera fuerza electoral en el estado.

Ahora bien, de los casi 337000 votos emitidos en el estado de Tlaxcala, los datos duros totales señalan que el PRI logró ganar los 3 distritos con la tercera y cuarta parte de los votos. Si consideramos porcentajes, en el caso del Distrito 1 el PRI ganó con el 37\% de los votos, en el Distrito 2 con el $22 \%$ y en el 3 con el $26 \%$. Visto así, la "tendencia general" fue ganar en promedio con la tercera parte del electorado que votó a favor del PRI, manteniéndose mayor o menormente en cada distrito, lo cual habla de la fragmentación de voto, en una entidad donde el PRI es el partido en el poder y donde la elecciones estuvieron desprestigiadas por acusaciones de la oposición de compra de voto, uso de programas electorales y de la estructura del gobierno del estado con fines electorales. 
Incluso, lo que parece manifestarse en el caso de Tlaxcala para el proceso 2015 en las elecciones a diputados/as federales no es como tal un aplastante triunfo del PRI en el sentido de lograr una amplia cantidad de votos que llegue a rangos, por ejemplo, arriba del 70\% u 80\%, sino se insinúa más bien para el 2015 la existencia de una pluralidad política que, como ya se ha hecho notar en una sección anterior del artículo, prevalece en los procesos electorales tlaxcaltecas (a nivel de gobernador, en los municipios y en el congreso estatal) de forma creciente en al menos los últimos 15 años, tal y como lo han señalado diversas investigaciones (Rodríguez y Mora, 2003; Rodríguez y Veloz, 2011; Rodríguez y Veloz, 2014, Reyes, 2014; Bustamante y Linares, 2014).

Ahora bien, como ya se ha señalado en otras secciones del artículo, lo que está detrás de la pluralidad política que muestran los datos electorales, está el hecho de que la unidad partidaria, las alianzas entre partidos políticos, la intervención del ejecutivo de la entidad en los comicios y la actividad de personajes distinguidos en el ámbito político; han sido elementos determinantes en la construcción de diversas opciones políticas en Tlaxcala. Por ejemplo, lo que en el análisis de la selección de candidatos para el proceso electoral 2015 se desprende, es que justamente en el PRI el factor de unidad solicitado por el gobernador del estado permitió llegar con candidatos únicos a las elecciones. Pero no sólo esto, sino que incluso la definición de los candidatos provinieron del mismo ejecutivo estatal, lo que coadyuvó a la ausencia de conflictos y con ello a la disciplina en torno a los aspirantes a diputados como en el viejo PRI.

En el caso del PAN, resalta la influencia de los tres grupos políticos fuertes señalados líneas arriba, uno de ellos emanado de las filas del PRI y los otros dos conformados por panistas reconocidos en la entidad. El PT al incluir a una figura ajena al partido pero con amplio respaldo del grupo político del PAC, garantizaría la obtención de votos y fortalecería la conveniente relación con esa institución política. En el caso de MORENA se da un proceso de negociación entre los candidatos/as por distrito, presentándose en la última etapa como uno de los factores decisivos el liderazgo del dirigente nacional de ese partido. Los candidatos/as de MORENA dispusieron para su campaña tan sólo de 20 mil pesos para cada de distrito, lo cual determinó que sólo aquellos/as que realmente estaban convencidos/as se quedaran en la última fase. Cabe señalar la participación de personajes distinguidos en el escenario político tlaxcalteca como Martha Palafox, quién proveniente del PRI al cual renunció para convertirse en senadora del PT en el 2014, dimite también a éste partido para colaborar en las filas de MORENA en el 2015, como Promotora de la Soberanía Nacional. Sin duda la presencia de Palafox fue un factor decisivo para la obtención de votos para MORENA.

\section{Consideraciones finales}

Los candidatos y candidatas elegidas para cargos de elección popular en general tienen una larga trayectoria tanto de servicio público como de participación en los cargos políticos. Cada uno de los partidos políticos mostró sus particularidades en la elección de candidatos. En el PAN aunque formalmente se incluyó a los militantes a partir de asambleas la trayectoria de los candidatos aunado a la cercanía con los grupos políticos al interior del partido determinaron la elección interna de los candidatos. En el caso de MORENA la honradez, presencia y/o trayectoria fueron fundamentales para la elección de sus candidatos/as; mientras que en el PRI la trayectoria partidaria y trabajo en el gobierno pesaron para los/ las militantes del partido en el poder, partido que conoce el terreno político y utiliza todos los recursos a 
su alcance para lograr sus objetivos electorales; en tanto que el PT en aras de mantener su permanencia desconoció a su militancia y echó mano de alianzas estratégicas que tuvieron éxito para su permanencia en el estado pero que minaron la relación con sus militantes.

En todos los casos destaca la importante presencia del Comité Ejecutivo Nacional, pero en el PAN, PRI y MORENA la normatividad interna determina algún grado de participación de la militancia, aunque finalmente la designación de los candidatos, sobre todo en el PAN y PRI, coincida con los intereses de los grupos y en MORENA con los liderazgos carismáticos. En estos términos un caso aparte es el PT quien ajusta el perfil de sus candidatos conforme a una estrategia de permanencia en la que no es conveniente la inclusión de la militancia pero si el acercamiento a grupos políticos externos al partidos.

En resumen, uno de los retos centrales que siguen enfrentando todos los partidos políticos (nacionales y locales) es la construcción y mejoramiento de la calidad de la democracia a su interior. La evidencia empírica muestra a lo largo del texto la preeminencia -en menor o mayor medida- de los grupos políticos, las corrientes de opinión y los líderes morales quienes siguen teniendo un peso determinante en las decisiones sobre quiénes serán los candidatos y candidatas para los cargos de elección popular en la entidad. Es necesario pues, transitar a modelos partidistas, según los cuales, la militancia tenga una participación sustantiva y definitiva en la elección de los y las candidatas y que la participación de los líderes y grupos se supedite al interés de la mayoría.

La transición hacia la democracia, tan anhelada por amplios sectores de la sociedad civil mexicana, no es posible si no se arriba a una trasformación radical de los procesos internos de los partidos. Entre los procesos internos más importantes se encuentra el de la selección de los y las candidatos/as quiénes serán, ni más ni menos, los representantes de la ciudadanía en los asuntos públicos. La situación de emergencia nacional así lo requiere: en un escenario de reformas estructurales que empobrecen a la población, así como la perdida de legitimidad del gobierno federal por la prevalencia de una crisis de derechos humanos, afirmación frecuentemente hecha por instancias internacionales.

Si bien es innegable que en México tuvo lugar la alternancia no podemos decir lo mismo de la tan deseada transición hacia la democracia. Coincidimos con John M. Ackerman (2015) cuando señala que la transición democrática como proceso ha sido un mito, un deseo inacabado que sólo reseña el agotamiento del sistema político pues ha dejado intactas las redes de poder de los mismos de siempre. Esas redes de poder se expresan, material y simbólicamente, al interior de los partidos políticos. Particularmente, quizás, uno de los momentos cumbre es durante la selección de candidatos/as donde no sólo se ensancha la brecha entre la clase política y la militancia sino entre una realidad profundamente autoritaria y el ideal democrático.

\section{Referencias}

Ackerman, John. 2015. El mito de la transición democrática. México: Planeta.

Alcántara, Manuel y Lina Cabezas (edit.). 2013. Selección y elaboración de programas en los partidos políticos latinoamericanos. España: Tirant lo Blanch.

Bustamante, Carlos y Neil Linares. 2014. Competitividad electoral y alternancia en el congreso estatal de Tlaxcala, 1995-2013. En Alternancia y pluralidad política en Tlaxcala, coordinado por Raúl Rodríguez, Carlos Bustamante y Magdalena Sam. México: Universidad Autónoma de Tlaxcala-Ediciones EON, 67-88. 
Cárdenas, Jaime. 2001. Partidos políticos y democracia. Cuadernos de Divulgación de la Cultura Democrática. núm. 8. Ciudad de México: Instituto Federal Electoral.

Cazarín, Angélica. 2010. Elecciones intermedias en Tlaxcala 2009. En México 2009: elecciones y partidos Estudios de caso, coordinados por René Valdiviezo y Jorge David. México: BUAP-SOMEE, 161-185.

Cordera, Rolando y Adolfo Sánchez. 1996. Sobre la actualidad de la transición mexicana. Frontera Norte, 8 (16): 7-19.

Duverger, Maurice. 2002. Los partidos políticos. México: FCE.

Elizondo, Carlos y Benito Nacif (comps.). 2006. Lecturas sobre el cambio político en México. México: FCE-CIDE.

Partido Acción Nacional. 2013. ESTATUTOS GENERALES DEL PARTIDO ACCIÓN NACIONAL APROBADOS POR LA XVII ASAMBLEA NACIONAL EXTRAORDINARIA. Estatutos Vigentes. Texto aprobado por la XVII Asamblea Nacional Extraordinaria y publicado en el Diario Oficial de la Federación el 5 de noviembre de 2013. Disponibles en: https://www.pan.org.mx/documentos-basicos/estatutos/ Partido Revolucionario Institucional. 2014. ESTATUTOS DEL PARTIDO REVOLUCIONARIO INSTITUCIONAL. Aprobados por el Consejo Político Nacional el 8 de agosto, declarados constitucional y legalmente válidos por el INE el 15 de octubre y publicados en el Diario Oficial de la Federación el 27 de octubre de 2014 Disponibles en:

http://pri.org.mx/TransformandoaMexico/Documentos/Estatutos2014.pdf

E-Tlaxcala. 2015. Emite PRI convocatoria para elegir a candidatos por dedazo. Diego Oaxaca. http://etlaxcala.mx/nota/2015-01-12/elecciones/emite-pri-convocatoria-para-elegir-candidatos-por-dedazo. (12 de enero de 2015).

E-Tlaxcala. 2015. Emite PAN convocatoria para candidatos a diputados plurinominales. http://e-tlaxcala.mx/nota/2014-12-29/pol\%C3\%ADtica/emite-el-pan-convocatoria-para-candidatos-diputados-plurinominales . (29 de diciembre del 2014).

Freidenberg, Flavia. 2003. Selección de candidatos y democracia interna en los partidos de América Latina. Lima: Transparencia Internacional e IDEA.

Freidenberg, Flavia. 2006. Democracia interna: un reto ineludible de los partidos políticos. Revista de derecho Electoral, 1 (1): 1-17.

Gangas, Pilar (s.f.). Los partidos políticos. https://campus.usal.es/ dpublico/areacp/materiales/Lospartidospoliticos.pdf

(15 de febrero de 2016)

Michels, Robert. 1983. Los partidos políticos. Buenos Aires: Amorrortu Editores.

Montero, José y Richard Gunther .2003. Los estudios sobre los partidos políticos: una revisión crítica. Colección Cuadernos de Trabajo. España: Universidad Autónoma de Madrid.

Reveles, Francisco. 2007. Teorías y realidades de los partidos políticos: una lectura desde México. Breviarios de Cultura Política Democrática, núm. 2.

http://www.corteidh.or.cr/tablas/24421.pdf

(29 de febrero de 2016)

Reyes, Juan. 2014. Tlaxcala 2013. Elecciones fuertemente disputadas. En Alternancia y pluralidad política en Tlaxcala, coordinado por Raúl Rodríguez, Carlos Bustamante y Magdalena Sam. México: Universidad Autónoma de Tlaxcala-Ediciones, EON.17-30. 
Rodríguez, Raúl y Juan Mora. 2003. Alternancia, gobierno dividido y pluralidad política en Tlaxcala (1995-2012). Contraste regional, 3 (5-6): 123-136.

Rodríguez, Raúl y Norma Veloz. 2011. Alternancia y pluralidad política en Tlaxcala: el regreso del PRI. El Cotidiano, 165: 81-93.

Rodríguez, Raúl y Norma Veloz. 2013. Alternancia y política en Tlaxcala: 1998-201. En Historia y contemporaneidad de la política en Tlaxcala, coordinado por Carlos Bustamante, María Magdalena Sam y Lucio Ernesto Maldonado. México: Universidad Autónoma de Tlaxcala, 107-126.

Rodríguez, Raúl y Norma Veloz. 2014. La consolidación del pluralismo moderado en el sistema político de Tlaxcala. En Alternancia y pluralidad política en Tlaxcala, coordinado por Raúl Rodríguez, Carlos Bustamante y Magdalena Sam. México: Universidad Autónoma de Tlaxcala-Ediciones EON, 31-54. Sartori, Giovanni. 1980. Partidos y sistemas de partidos. España: Alianza Editorial. Sartori Giovanni. 1995. Teoría de la democracia. España: Alianza Universidad, Ciencias Sociales. Valles, Joseph. 2006. Ciencia política. Una introducción. España: Ariel, Serie Ciencia Política.

\section{Anexo}

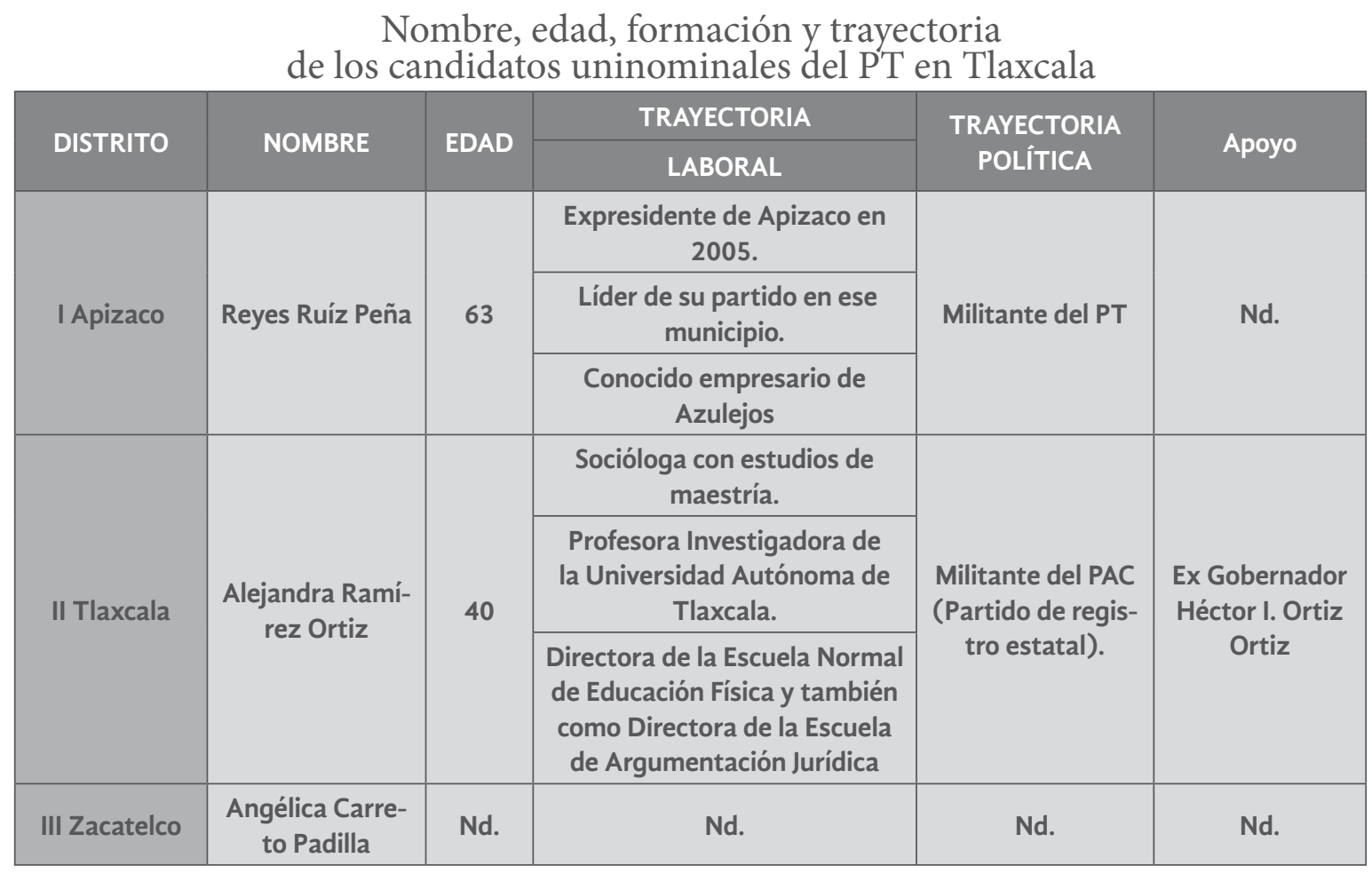

Fuente: INE y entrevistas. 
- Revista de Ciencias Sociales y Humanidades. ISSN-P: 0188-9834 ISSN-E: 2395-8669.

Nombre, edad, formación y trayectoria de los candidatos uninominales del PRI en Tlaxcala

\begin{tabular}{|c|c|c|c|c|c|}
\hline DISTRITO & NOMBRE & EDAD & TRAYECTORIA LABORAL & TRAYECTORIA POLÍTICA & Apoyo \\
\hline \multirow{6}{*}{ izaco } & \multirow{6}{*}{$\begin{array}{l}\text { Rosalinda Mu- } \\
\text { ñoz Sánchez }\end{array}$} & \multirow{6}{*}{36} & \multirow{6}{*}{$\begin{array}{l}\text { Directora del Fondo Macro } \\
\text { para el Desarrollo Integral de } \\
\text { Tlaxcala (FOMTLAX) }\end{array}$} & $\begin{array}{l}\text { Presidenta del Comité Mu- } \\
\text { nicipal del PRI en Apizaco }\end{array}$ & \\
\hline & & & & $\begin{array}{l}\text { Presidenta Municipal de } \\
\text { Tlaxco (2011-2013) }\end{array}$ & \\
\hline & & & & $\begin{array}{c}\text { Candidata a diputada local } \\
\text { (2013) }\end{array}$ & \\
\hline & & & & $\begin{array}{c}\text { Consejera estatal y nacional } \\
\text { del PRI }\end{array}$ & \\
\hline & & & & $\begin{array}{c}\text { Consejera Estatal en la Co- } \\
\text { misión de Procedimientos } \\
\text { Internos del PRI. }\end{array}$ & \\
\hline & & & & $\begin{array}{c}\text { Consejera Estatal de la } \\
\text { Confederación Nacional } \\
\text { Campesina (CNC) y del } \\
\text { Organismo Nacional de } \\
\text { Mujeres del PRI }\end{array}$ & \\
\hline \multirow{3}{*}{ II Tlaxcala } & \multirow{3}{*}{$\begin{array}{l}\text { Edith Anabel } \\
\text { Alvarado } \\
\text { Varela }\end{array}$} & \multirow{3}{*}{36} & Maestra. & $\begin{array}{c}\text { Consejera Política Estatal y } \\
\text { Nacional del PRI }\end{array}$ & \\
\hline & & & $\begin{array}{c}\text { Integrante del Equipo de } \\
\text { Asesores del exgobernador } \\
\text { del Edo. De México Enrique } \\
\text { Peña Nieto. }\end{array}$ & $\begin{array}{l}\text { Secretaria General de la } \\
\text { CNOP del PRI. }\end{array}$ & \\
\hline & & & \begin{tabular}{|c|} 
Secretaria Particular del Go- \\
bernador Mariano González \\
Zarur
\end{tabular} & $\begin{array}{l}\text { Presidenta de la Comi- } \\
\text { sión Nacional de Jóvenes } \\
\text { Priístas. }\end{array}$ & \\
\hline \multirow{4}{*}{ III Zacatelco } & \multirow{4}{*}{$\begin{array}{l}\text { Ricardo Gar- } \\
\text { cía Portilla }\end{array}$} & \multirow{4}{*}{42} & Nivel de Maestría. & $\begin{array}{l}\text { Secretario Adjunto de la } \\
\text { Presidencia Estatal. }\end{array}$ & \multirow{4}{*}{$\begin{array}{l}\text { Mariano } \\
\text { González } \\
\text { Zarur }\end{array}$} \\
\hline & & & $\begin{array}{l}\text { Secretario de Paneación y } \\
\text { Finanzas del Gobierno del } \\
\text { Edo. }\end{array}$ & Dirigente Estatal del PRI. & \\
\hline & & & Asesor de la SHCP. & $\begin{array}{c}\text { Secretario Técnico de la LVII } \\
\text { legislatura del Estado de } \\
\text { Tlaxcala. }\end{array}$ & \\
\hline & & & $\begin{array}{l}\text { Asesor en la Camara de } \\
\text { Senadores. }\end{array}$ & Consejero Político del PRI & \\
\hline
\end{tabular}

Fuente: INE y entrevistas. 
- Revista de Ciencias Sociales y Humanidades. ISSN-P: 0188-9834 ISSN-E: 2395-8669.

Nombre, edad, formación y trayectoria

de los candidatos uninominales del PAN en Tlaxcala

\begin{tabular}{|c|c|c|c|c|c|}
\hline DISTRITO & NOMBRE & EDAD & TRAYECTORIA LABORAL & TRAYECTORIA POLÍTICA & Apoyo \\
\hline \multirow{3}{*}{ I Apizaco } & \multirow{3}{*}{$\begin{array}{l}\text { Orlando Santacruz } \\
\text { Carreño }\end{array}$} & \multirow{3}{*}{ Nd. } & Abogado. & $\begin{array}{l}\text { Diputado Local por el Distri- } \\
\text { to XV de la LIX Legislatura } \\
\text { por PAN. Consejero Jurídico } \\
\text { del Gobierno del Estado. }\end{array}$ & \multirow{3}{*}{$\begin{array}{l}\text { Adriana } \\
\text { Davila Fer- } \\
\text { nández }\end{array}$} \\
\hline & & & $\begin{array}{c}\text { Expresidente Municipal } \\
\text { de Apizaco }\end{array}$ & $\begin{array}{c}\text { Director Jurídico del Gobier- } \\
\text { no del Estado. }\end{array}$ & \\
\hline & & & & $\begin{array}{l}\text { Director Jurídico del Instituto } \\
\text { Electoral de Tlaxcala. }\end{array}$ & \\
\hline \multirow{4}{*}{ II Tlaxcala } & \multirow{4}{*}{$\begin{array}{l}\text { Miguel Angel Polvo } \\
\text { Rea }\end{array}$} & \multirow{4}{*}{27} & $\begin{array}{l}\text { Abogado, notario y } \\
\text { actuario. }\end{array}$ & $\begin{array}{c}\text { Equipo de campaña del Go- } \\
\text { bernador de Puebla, Rafael } \\
\text { Moreno Valle (2010). }\end{array}$ & \multirow{4}{*}{$\begin{array}{l}\text { Rafael Mo- } \\
\text { reno Valle }\end{array}$} \\
\hline & & & $\begin{array}{c}\text { Presidente de la Asocia- } \\
\text { ción civil “Jóvenes por } \\
\text { México”. }\end{array}$ & $\begin{array}{l}\text { Presidente Municipal de la } \\
\text { Magdalena Tlaltelulco, Tlax. }\end{array}$ & \\
\hline & & & $\begin{array}{l}\text { Jefe del Departamento } \\
\text { de Vinculación Social en } \\
\text { la Secretaría General de } \\
\text { Gobierno de Puebla. }\end{array}$ & & \\
\hline & & & $\begin{array}{c}\text { Subdirector de Delega- } \\
\text { ciones de la Secretaría de } \\
\text { Desarrollo Social. }\end{array}$ & & \\
\hline \multirow{6}{*}{ III Zacatelco } & \multirow{6}{*}{$\begin{array}{l}\text { Lilia Caritina Olvera } \\
\text { Coronel }\end{array}$} & \multirow{6}{*}{ Nd. } & $\begin{array}{l}\text { Profesora Educadora, } \\
\text { Licenciada en Literatura } \\
\text { Española, con estudios } \\
\text { de maestría }\end{array}$ & $\begin{array}{l}\text { Diputada Local por el XIII } \\
\text { Distrito (presidenta de } \\
\text { la Comisión de Equidad y } \\
\text { Género, Presidenta de la } \\
\text { Junta de Coordinación y } \\
\text { Concertación Política). }\end{array}$ & \\
\hline & & & $\begin{array}{l}\text { Secretaria Sindical del } \\
\text { Grupo II de la Comisión } \\
\text { Mixta de Escalafón, SEPE- } \\
\text { USET. }\end{array}$ & & \\
\hline & & & & $\begin{array}{c}\text { Ex Presidenta Municipal de } \\
\text { Nanacamilpa de Mariano } \\
\text { Arista. }\end{array}$ & \\
\hline & & & $\begin{array}{c}\text { Coordinadora de turismo } \\
\text { infantil y juvenil, SEPE- } \\
\text { USET. }\end{array}$ & & \\
\hline & & & & $\begin{array}{c}\text { Vicepresidenta de la Región } \\
8 \text { de la COPECOL. }\end{array}$ & \\
\hline & & & $\begin{array}{c}\text { Titular del departamento } \\
\text { de incorporación, revali- } \\
\text { dación y equivalencia de } \\
\text { la USET }\end{array}$ & & \\
\hline
\end{tabular}

Fuente: INE y entrevistas. 
- Revista de Ciencias Sociales y Humanidades. ISSN-P: 0188-9834 ISSN-E: 2395-8669.

Nombre, edad, formación y trayectoria

de los candidatos uninominales de MORENA en Tlaxcala

\begin{tabular}{|c|c|c|c|c|c|}
\hline DISTRITO & NOMBRE & EDAD & $\begin{array}{c}\text { FORMACIÓN PROFESIO- } \\
\text { NAL Y/O LABORAL }\end{array}$ & TRAYECTORIA POLITICA & APOYO \\
\hline \multirow{15}{*}{ I Apizaco } & \multirow{15}{*}{$\begin{array}{c}\text { Alfonso Sánchez } \\
\text { Anaya }\end{array}$} & \multirow{15}{*}{74} & $\begin{array}{c}\text { Médico Veterinario Zoo- } \\
\text { tecnista }\end{array}$ & $\begin{array}{c}\text {-Consejo Consultivo de } \\
\text { MORENA }\end{array}$ & \multirow{15}{*}{ AMLO } \\
\hline & & & -Secretario de Finanzas & $\begin{array}{c}\text {-Comisión de Refundación } \\
\text { del PRD en el } 2009\end{array}$ & \\
\hline & & & $\begin{array}{c}\text {-Coordinador del Comité } \\
\text { de Planeación para el } \\
\text { Desarrollo del Estado }\end{array}$ & -Consejero Nacional del PRD & \\
\hline & & & $\begin{array}{c}\text {-Secretario de Desarrollo } \\
\text { Económico }\end{array}$ & $\begin{array}{l}\text {-Miembro de la Comisión } \\
\text { política Nacional de PRD }\end{array}$ & \\
\hline & & & $\begin{array}{c}\text { Gobernador del Estado } \\
\text { de Tlaxcala }\end{array}$ & $\begin{array}{c}\text {-Comisión política Nacional } \\
\text { del PRI }\end{array}$ & \\
\hline & & & Fundador de la CONAGO & $\begin{array}{c}\text { - Director del Centro de Es- } \\
\text { tudios Políticos, Económicos } \\
\text { y Sociales en el Estado de } \\
\text { Tlaxcala }\end{array}$ & \\
\hline & & & $\begin{array}{c}\text { Diputado federal LVI } \\
\text { Legislatura }\end{array}$ & $\begin{array}{c}\text { Presidente del Comité } \\
\text { Directivo Estatal del PRI en } \\
\text { Tlaxcala }\end{array}$ & \\
\hline & & & Senador de la República & $\begin{array}{c}\text { Dirigente nacional de la Uni- } \\
\text { dad Nacional Veterinaria }\end{array}$ & \\
\hline & & & Gobierno Federal: & $\begin{array}{c}\text {-Presidente Nacional del } \\
\text { Foro de Profesionales y } \\
\text { Técnicos }\end{array}$ & \\
\hline & & & $\begin{array}{c}\text { Director General de } \\
\text { Fomento Ganadero de la } \\
\text { SARH. }\end{array}$ & & \\
\hline & & & $\begin{array}{l}\text { Director General de } \\
\text { Ganadería de la SARH }\end{array}$ & & \\
\hline & & & $\begin{array}{c}\text {-Director de Agricultura y } \\
\text { Ganadería }\end{array}$ & & \\
\hline & & & $\begin{array}{c}\text {-Delegado de la SARH en } \\
\text { Tlaxcala }\end{array}$ & & \\
\hline & & & Iniciativa privada: & & \\
\hline & & & $\begin{array}{l}\text { Director de la División } \\
\text { Agropecuaria de los labo- } \\
\text { ratorios SINTEX S.A. para } \\
\text { México, Centroamérica y } \\
\text { el Caribe }\end{array}$ & & \\
\hline
\end{tabular}


- Revista de Ciencias Sociales y Humanidades. ISSN-P: 0188-9834 ISSN-E: 2395-8669.

\begin{tabular}{|c|c|c|c|c|c|}
\hline DISTRITO & NOMBRE & EDAD & $\begin{array}{l}\text { FORMACIÓN PROFESIO- } \\
\text { NAL Y/O LABORAL }\end{array}$ & TRAYECTORIA POLİTICA & APOYO \\
\hline \multirow{6}{*}{ II Tlaxcala } & \multirow{6}{*}{$\begin{array}{c}\text { Marco Antonio } \\
\text { Castillo Hernán- } \\
\text { dez }\end{array}$} & \multirow{6}{*}{68} & $\begin{array}{c}\text { Médico Veterinario Zoo- } \\
\text { tecnista/UNAM }\end{array}$ & $\begin{array}{l}\text {-Coordinador de Campaña } \\
\text { de Alfonso Sánchez Anaya }\end{array}$ & \multirow{6}{*}{ AMLO } \\
\hline & & & $\begin{array}{l}\text {-Diplomado en Adminis- } \\
\text { tración Pública/UAT }\end{array}$ & $\begin{array}{c}\text {-Coordinador de campaña } \\
\text { de diputados y presidentes } \\
\text { municipales }\end{array}$ & \\
\hline & & & $\begin{array}{c}\text {-Maestría en Economía/ } \\
\text { Chapingo }\end{array}$ & $\begin{array}{c}\text {-Coordinador de asesores } \\
\text { del Gobernador Alfonso } \\
\text { Sánchez Anaya }\end{array}$ & \\
\hline & & & $\begin{array}{c}\text {-Maestría en Análisis } \\
\text { Regional/UAT }\end{array}$ & -Director del Cecyte & \\
\hline & & & & $\begin{array}{l}\text {-Representante de Taxcala } \\
\text { frente a la Coordinación de } \\
\text { Planeación Estratégica de la } \\
\text { Presidencia de la República }\end{array}$ & \\
\hline & & & & -Profesor Universitario & \\
\hline \multirow[b]{3}{*}{ III Zacatelco } & \multirow[b]{3}{*}{$\begin{array}{l}\text { Ana Lilia Rivera } \\
\text { Rivera }\end{array}$} & \multirow[b]{3}{*}{ Nd. } & \multirow[b]{3}{*}{ Abogada } & $\begin{array}{c}\text { Consejera Nacional de } \\
\text { MORENA. }\end{array}$ & \multirow[b]{3}{*}{ AMLO } \\
\hline & & & & $\begin{array}{c}\text { Diputada local del PRD } \\
(2008-2011) .\end{array}$ & \\
\hline & & & & $\begin{array}{c}\text { Propuso la Ley de Fomento } \\
\text { y Protección al Maíz como } \\
\text { Patrimonio Originario en } \\
\text { Diversificación Constante y } \\
\text { Alimentario para el Estado } \\
\text { de Tlaxcala }\end{array}$ & \\
\hline
\end{tabular}

Fuente: Página del INE y entrevistas. 